RESIDENT

\& FELLOW

SECTION

Section Editor

Mitchell S.V. Elkind,

MD, MS
Child Neurology:

\section{Alternating hemiplegia of childhood}

Jeffrey R. Tenney, MD,

$\mathrm{PhD}$

Mark B. Schapiro, MD

Address correspondence and reprint requests to Dr. Jeffrey R. Tenney, Department of Neurology, Cincinnati Childrens Hospital Medical Center, 3333

Burnet Ave, Cincinnati, $\mathrm{OH}$

45229-3039

jeffrey.tenney@cchmc.org
Alternating hemiplegia of childhood (AHC) is a rare disorder characterized by recurrent attacks of hemiplegia affecting either side of the body, abnormalities of ocular movement, movement disorders, and progressive developmental delay. Children with AHC often have a delay in diagnosis or are misdiagnosed. A broad differential diagnosis is necessary when considering this condition. The clinical features of AHC were first described more than 3 decades ago but its cause remains largely unknown and there is little treatment evidence available. Early diagnosis and multicenter collaboration are necessary to better understand the prognosis of $\mathrm{AHC}$ and develop more effective treatments.

CLINICAL CASE, PART I A 12-month-old boy was sent for neurologic consultation after an episode of transient right-sided paralysis. His mother states that during the episode he was fully conscious but half of his body was paralyzed and he appeared to have a stroke. This episode lasted 6 hours and resolved when he slept. He was at his normal baseline upon waking. His mother states that the patient had a similar episode, although occurring on the left side, when he was 4 months old. There was a family history of migraines but no other neurologic disorders. $\mathrm{He}$ achieved normal developmental milestones during the first year of life and at 12 months of age was walking independently and had some words. Neurologic examination, done once symptoms had resolved, was normal.

Differential diagnosis. Acute focal weakness in a child has many serious etiologies that must be investigated (table 1). The evaluation is focused on excluding serious or treatable causes. Evaluation should begin with MRI, magnetic resonance angiography (MRA), and magnetic resonance spectroscopy to exclude structural, vascular, and metabolic disorders such as mitochondrial myopathy, encephalopathy, lactic acidosis, and stroke (MELAS) and pyruvate dehydrogenase deficiency. Other testing should include EEG, metabolic screening with urine organic acids, quanti- tative serum and CSF amino acids, acylcarnitine, lactate/pyruvate (serum and CSF), hypercoagulable studies, erythrocyte sedimentation rate, and transferrin isoelectric focusing.

CLINICAL CASE, PART II On diagnostic testing, brain MRI, MRA, and 2 routine EEGs were normal. Laboratory testing included normal very long chain fatty acids; quantitative serum amino acids, acylcarnitine, ammonia, lactate, and pyruvate; urine organic acids; CSF amino acids; thyroid function studies; and serum transferrin isoelectric focusing assay.

Based on the clinical history, normal neurologic examination between episodes, and negative testing, the patient was given a diagnosis of AHC. Over the next several years, the patient continued to have episodes of alternating hemiplegia and by 2 years old he began to have episodes of quadriplegia. His attacks clustered during the summer months and were triggered by warm ambient temperature and bright sunlight. As he became older, he was able to verbalize that he was having headaches either at the time of his attacks or independent of them. His weakness and headache were frequently relieved by sleep. Analysis of genes that have been associated with AHC, including SCN1A, CACNA1A, and ATP1A2, showed no mutations. The patient was started on nifedipine as prophylaxis for his attacks, but this resulted in only a modest improvement.

DISCUSSION Epidemiology. AHC is a rare disorder that was first reported by Verret and Steele ${ }^{1}$ in 1971. It has a reported incidence of 1 in 1,000,000 children but this may be an underestimate due to misdiagnosis and variability in the clinical presentation. ${ }^{2}$ Since this disease occurs so infrequently and is variable in presentation, knowledge of the clinical characteristics, response to treatment, and prognosis is based on a few small cohort studies. ${ }^{3,4}$

Clinical characteristics. The first report of the disorder in 1971 included 8 children with intermittent hemiparesis of varying severity since infancy. Some 


Table $1 \quad$ Differential diagnosis of acute focal
weakness in childhood

of these children also had developmental delay, dysarthria, choreoathetosis, or dystonia. ${ }^{1}$ Clinical diagnostic criteria of classic AHC have since been established (table 2). ${ }^{5}$

The hemiplegic attacks usually last a few minutes to several days and are associated with slowly progressive neurologic deficits over years. ${ }^{3}$ The onset of the syndrome begins with abnormal ocular movements (nystagmus, esotropia, exotropia) or dystonia in a majority of patients by 3 months of age. ${ }^{3,4}$ Hemiple-

Table 2 Diagnostic criteria for alternating hemiplegia of childhood 5
1. Symptoms before age 18 months
2. Repeated attacks of hemiplegia that alternate in laterality
3. Episodes of quadriplegia as a separate attack or generalization of a hemiplegic attack
4. Relief from symptoms upon sleeping
5. Other paroxysmal symptoms including dystonic spells, oculomotor abnormalities, or autonomic symptoms either concurrent with attacks or independently
6. Evidence of developmental delay or neurologic findings such as choreoathetosis, dystonia, or ataxia

gic attacks occur by 6 months of age in more than half of the patients who have been studied. ${ }^{3,4}$ Motor findings during an attack have been described as flaccid, areflexic paralysis. ${ }^{6}$ Attacks are frequently associated with triggers, most commonly environmental (temperature extremes, odors) but also water exposure, physical activities (exercise, swinging), lights (sunlight, fluorescent bulbs), or foods (chocolate, food dye)..$^{4}$

Pathogenesis. The etiology of AHC remains unclear, but it is likely a symptom complex with multiple causes. Neurophysiologic recordings during an attack have shown impaired brainstem circuits. ${ }^{7}$ In contrast, FDG-PET during the interictal period showed low glucose metabolism in the frontal lobes and putamen with normal metabolism in the brainstem which could explain the progressive neurologic symptoms reported with AHC. ${ }^{8}$ Microscopic postmortem evaluation of patients with AHC has shown abnormal vascular smooth muscle cells which could result in a functional vascular disorder causing transient small vessel dysfunction in the brain. ${ }^{9}$

The attacks occurring in AHC and familial hemiplegic migraine (FHM) are clinically similar, raising the question of a channelopathy as the underlying dysfunction for both. FHM has been associated with several ion transport genes including SCN1A (sodium channel, neuronal type 1 , alpha subunit), CACNA1A (calcium channel, voltage dependent, $\mathrm{P} / \mathrm{Q}$ type, alpha-1A subunit), and ATP1A2 (ATPase, $\mathrm{Na}+/ \mathrm{K}+$ transporting, alpha-2 polypeptide). AHC, in uncommon familial cases, has been reported to be associated with mutations in $C A C N A 1 A$, a calcium channel gene, and $A T P 1 A 2$, a sodium potassium ATPase gene. ${ }^{10,11}$ These gene mutations have yet to be reported with sporadic AHC but given its response to calcium channel blockers a channelopathy is possible.

Treatment. Treatment of AHC is divided into acute management of attacks and episode prophylaxis. Acute management consists of removing known triggers and the early facilitation of sleep. Some authors have advocated the use of buccal midazolam or rectal diazepam to provide rapid sedation. ${ }^{2}$

Episode prophylaxis should consist of avoiding known triggers as well as long-term drug treatment. A wide range of medications has been proposed for AHC but in our experience calcium channel blockers are the most effective. The most commonly used medication is flunarizine, a calcium channel blocker, in a dose of 5 to $20 \mathrm{mg}$ daily. ${ }^{2,4,6}$ This has been reported to decrease the frequency and severity of attacks, but not to stop them completely. Other proposed treatments have included beta blockers, an- 
ticonvulsants, and other medications such as methysergide, amantadine, aripiprazole, and haloperidol, but these are not frequently used. ${ }^{2}$

Prognosis. The long-term outcome of patients with $\mathrm{AHC}$ is frequently poor because of associated developmental delays and stepwise deterioration after severe attacks., ${ }^{2,4}$ it is unclear if pharmacologic intervention helps to improve learning, but lessening the severity and frequency of attacks may lead to an improved quality of life.

It has been reported in the largest cohort studies that almost half of children with AHC will develop epilepsy, with seizures that are distinguishable from their attacks. ${ }^{2,4}$

FUTURE PERSPECTIVES AHC is a rare but serious disorder in the pediatric population. It can greatly impact the quality of life for patients and their families. Health care dollars spent on patients with this disorder could be substantial given their frequent emergency room visits, hospitalizations, and broad diagnostic evaluations.

The complex and seemingly progressive nature of AHC makes it imperative that continued research into the pathophysiology and treatment of the disorder is performed. This includes randomized, controlled trials with sufficient numbers of patients. The formation of a multicenter consortium could help to collect the experience of different hospitals and enable a large group of patients to be followed over time.

\section{REFERENCES}

1. Verret S, Steele JC. Alternating hemiplegia in childhood: a report of eight patients with complicated migraine beginning in infancy. Pediatrics 1971;47:675-680.

2. Neville BR, Ninan M. The treatment and management of alternating hemiplegia of childhood. Dev Med Child Neurol 2007;49:777-780.

3. Mikati MA, Kramer U, Zupanc ML, et al. Alternating hemiplegia of childhood: clinical manifestations and longterm outcome. Pediatr Neurol 2000;23:134-141.

4. Sweney MT, Silver K, Gerard-Blanluet M, et al. Alternating hemiplegia of childhood: Early characteristics and evolution of a neurodevelopmental syndrome. Pediatrics 2009;123:e534-e541.

5. Bourgeois M, Aicardi J, Goutieres F. Alternating hemiplegia of childhood. J Pediatr 1993;122:673-679.

6. Kannavakis E, Xaidara A, Papadimitriou A, et al. Alternating hemiplegia of childhood: a syndrome inherited with an autosomal dominant trait. Dev Med Child Neurol 2003; 45:833-836.

7. Rinalduzzi S, Valeriani M, Vigevano F. Brainstem dysfunction in alternating hemiplegia of childhood: a neurophysiological study. Cephalalgia 2006;26:511-519.

8. Sasaki M, Sakuma H, Fukushima A, et al. Abnormal cerebral glucose metabolism in alternating hemiplegia of childhood. Brain Dev 2009;31:20-26.

9. Auvin S, Joriot-Chekaf S, Cuvellier JC. Small vessel abnormalities in alternating hemiplegia of childhood. Neurology 2006;66:499-504.

10. de Vries B, Stam AH, Beker F, et al. CACNA1A mutation linking hemiplegic migraine and alternating hemiplegia of childhood. Cephalalgia 2008;28:887-891.

11. Swoboda KJ, Kanavakis E, Xaidara A, et al. Alternating hemiplegia of childhood or familial hemiplegic migraine? A novel ATP1A2 mutation. Ann Neurol 2004;55:884887. 


\title{
Neurology
}

\author{
Child Neurology: Alternating hemiplegia of childhood \\ Jeffrey R. Tenney and Mark B. Schapiro \\ Neurology 2010;74;e57-e59 \\ DOI 10.1212/WNL.0b013e3181d7d85b
}

This information is current as of April 5, 2010

\section{Updated Information \& Services}

References

Citations

Subspecialty Collections

Permissions \& Licensing

Reprints including high resolution figures, can be found at: http://n.neurology.org/content/74/14/e57.full

This article cites 11 articles, 1 of which you can access for free at: http://n.neurology.org/content/74/14/e57.full\#ref-list-1

This article has been cited by 2 HighWire-hosted articles: http://n.neurology.org/content/74/14/e57.full\#\#otherarticles

This article, along with others on similar topics, appears in the following collection(s):

All Pediatric

http://n.neurology.org/cgi/collection/all_pediatric

Childhood stroke

http://n.neurology.org/cgi/collection/childhood_stroke

Developmental disorders

http://n.neurology.org/cgi/collection/developmental_disorders

Pediatric headache

http://n.neurology.org/cgi/collection/pediatric_headache

Information about reproducing this article in parts (figures,tables) or in its entirety can be found online at:

http://www.neurology.org/about/about_the_journal\#permissions

Information about ordering reprints can be found online:

http://n.neurology.org/subscribers/advertise

Neurology ${ }^{\circledR}$ is the official journal of the American Academy of Neurology. Published continuously since 1951, it is now a weekly with 48 issues per year. Copyright . All rights reserved. Print ISSN: 0028-3878. Online ISSN: 1526-632X.

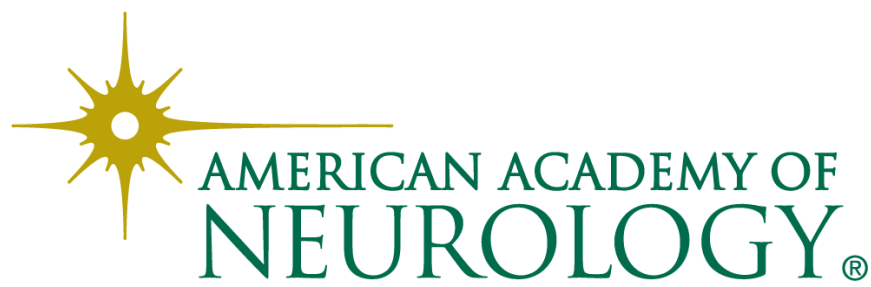

